\title{
RESPONSABILIDAD POLÍTICA DEL RÉGIMEN CONSTITUCIONAL IMPERIAL BRASILERO DE 1824
}

POLITICAL RESPONSIBILITY IN THE BRAZILIAN IMPERIAL CONSTITUTION OF 1824

\author{
Alexandre Walmott BORGES ${ }^{1}$ \\ Fabiana Angélica Pinheiro CÂMARA ${ }^{2}$ \\ Wilcon Algelis Luciano ABREU ${ }^{3}$
}

ISSUE DOI: $10.21207 / 1983.4225 .830$

\begin{abstract}
RESUMO
El objeto de investigación de este artículo son las formas de responsabilidad política, funcional y administrativa de los agentes públicos en el régimen constitucional brasilero del Imperio (1824 hasta 1889). El abordaje del tema se hace por contextualización de diversas formas de responsabilidad política, funcional y administrativa como formas propias del Estado de Derecho. El texto inserta estas
\end{abstract}

\footnotetext{
${ }^{1}$ Profesor de los programas de maestría en Derecho y Gestión Organizacional de la UFU - Universidad Federal de Uberlândia. Pro-fesor visitante de la maestría en derecho de la UNESP - Universidad Estadual Paulista Júlio de Mezquita $\mathrm{F}^{\circ}$. Doctor en Derecho por la UFSC - Universidad Federal de Santa Catarina. Doctorado en Historia por la UFU - Universidad Federal de Uberlândia. Investigador líder del Laboratorio Americano de Estudios Constitucionales Compara-dos. Investigación del artículo realizada con recursos de la FAPEMIG - Fundación de Apoyo a la investigación en el Estado de MG y de Seminario patrocinado por CAPES. walmott@gmail.com.

${ }^{2}$ Doctorado en Historia Social por la UFU - Universidad Fe-deral de Uberlândia. Graduada en Administración por la Universidad de Viena. Maestra en Negocios Internacionales por la Universidad de Reading, Inglaterra. Investigador del Laboratorio Americano de Estu-dios Constitucionales Comparados. camara.fabiana@gmail.com. Av. João Naves de Ávila n ${ }^{\circ} 2121$, edificio de la rectoría, $3{ }^{\circ}$ piso, Propp, Uberlândia, MG.

${ }^{3}$ Mestrando de la UFU - Universidad Federal de Uberlândia. lucianowilcon@gmail.com.

El presente trabajo fue realizado con apoyo de la Coordinación de Perfeccionamiento de Personal de Nivel Superior - Brasil (CAPES).
} 
diversas formas de responsabilidad dentro del estrato temporal e histórico del régimen constitucional de 1824, con la narración de estas formas de acuerdo con las propiedades e indicadores descriptivos de la materialidad de las normas de aquel período. Después, se hace la descripción cualitativa de las diversas formas de responsabilidad de este sistema constitucional, ordenándolas de acuerdo con los agentes envueltos y de acuerdo con el ejercicio funcional de los agentes, presentando diversos sistemas peculiares de responsabilidad a los diversos agentes públicos de aquel período. Los resultados provisionales muestran que el sistema imperial de responsabilidad sirvió de modelo a los sistemas de responsabilidad del período republicano, inclusive parcialmente al actual sistema de responsabilidad vigente en la constitución de 1988. A lo menos los prototipos procesales y de ordenación de las normas de derecho material fueran institucionalizados en el régimen de 1824. Hay una parte de contextualización de la responsabilidad del Estado de Derecho, la investigación teórica, con revisión bibliográfica sobre el tema. En la secuencia, el proceso de realización del texto es inductivo, extrayendo de las fuentes documentarias descripciones exhaustivas sobre las formas de responsabilidad adoptadas, en concreto, en el régimen constitucional de 1824. Las fuentes de investigación fueron las bibliográficas de teoría política, teoría constitucional, especialmente en el abordaje y contextualización de Estado de Derecho, con periódicos como fuentes auxiliares; en la parte de problematización de las formas de responsabilidad del régimen de 1824, la fuente principal son los documentos legislados y secundariamente los periódicos.

Palavras-chave:

\begin{abstract}
The purpose of this article is to analyse the forms of political, administrative and functional liability of Estate agents in the Brazilian constitutional system of the Empire period (from 1824 to 1889). The subject approach intends to present an overview of the various forms of political and functional liability in the period of the Brazilian Empire. Provisional results show that the imperial liability system served as model to the liability system of the Republican period, including the current partially effective liability system in the Constitution of 1988. There is a theoretical research in the context of liability in the rule of law with literature review on the topic. Subsequently, the writing process of this text is inductive, by extracting from documentary sources comprehensive descriptions of the liability forms adopted in the concrete constitutional regime of 1824. The research sources were literature review of political and constitutional theories, with periodical as auxiliary sources; when it was questioned on the liability forms in the 1824 regime, the main sources are laws and secondarily Periodicals.
\end{abstract}

Keywords:

\title{
INTRODUCCIÓN
}

El objeto de investigación de este artículo son las formas de responsabilidad política, funcional e administrativa de los agentes públicos en el regirme constitucional brasilero del Imperio (1824 hasta 1889). El abordaje del tema se hace por contextualización de las diversas formas de responsabilidad política, funcional e administrativa como formas propias del Estado de Derecho. El texto inserta estas diversas formas de responsabilidad dentro del estrato temporal e histórico del régimen constitucional de 1824, con la narración de estas formas de acuerdo con las propiedades e indicadores descriptivos de la materialidad de las normas de aquel período. 
Después, se hace la descripción cualitativa de las diversas formas de responsabilidad de este sistema constitucional, ordenándolas de acuerdo con los agentes envueltos y de acuerdo con el ejercicio funcional de los agentes, presentando diversos sistemas peculiares de responsabilidad a los diversos agentes públicos de aquel período. Los resultados provisionales muestran que el sistema imperial de responsabilidad serbio de modelo a los sistemas de responsabilidad del período republicano, inclusive parcialmente al actual sistema de responsabilidad vigente en la constitución de 1988. Al menos los prototipos procesales y de ordenación de las normas de derecho material fueron institucionalizados en el régimen de 1824.

En la parte de contextualización de la responsabilidad del Estado de Derecho, trabajamos la investigación teórica con revisión bibliográfica sobre el tema. Por tanto, el proceso de realización del texto es inductivo, extrayendo de las fuentes documentarias descripciones exhaustivas sobre las formas de responsabilidad adoptadas, en concreto, en el régimen constitucional de 1824. Las fuentes de investigación fueron las bibliográfica de teoría política, teoría constitucional, especialmente en el abordaje de contextualización de Estado de Derecho, con periódicos como fuentes auxiliares; en la parte de problematización de las formas de responsabilidad en el régimen de 1824, la fuente principal son los documentos legislados y secundariamente los periódicos.

\section{LA RESPONSABILIDAD POLÍTICA Y FUNCIONAL EN EL AMBIENTE DE ESTADO DE DERECHO.}

La idea general del Estado de Derecho y la sujeción del Estado a las directrices estipuladas por las normas jurídicas. Esta idea general es descompuesta en algunas otras características esenciales para la descripción de un Estado de Derecho. Son consideradas características del Estado de Derecho la existencia de una constitución vinculante de los órganos del Estado; la existencia de una constitución con normas protectoras de derechos fundamentales; la participación funcional de los órganos del Estado la posibilidad de alguna forma de control de constitucionalidad de los actos

\footnotetext{
${ }^{4}$ Como disciplina del art. $5^{\circ}$ de la constitución de Suíça: ' All of the state are based on and limited by law. State activities must be conducted in the public interest and be proportionate to the ends sought. State institutions and private persons shall act in good faith (THE FEDERAL COUNCIL, 2016).
} 
y normas; la autonomía funcional de los órganos del Estado; y la responsabilidad del Estado y los agentes del Estado (ROIG, 1999; MIRANDA, 2002; BINGHAM, 2011).

Este último aspecto, la responsabilidad del Estado, se puede realizar en diversos campos o de diversas formas. La existencia de formas de responsabilidad civil del Estado, e.g., permite caracterizar este Estado como un Estado de Derecho. La responsabilidad puede ser tanto de la persona jurídica del Estado como del agente estatal investido de la función ${ }^{5}$. Además de las formas de responsabilidad civil, el Estado de Derecho también presenta formas de responsabilidad penal de sus agentes. Tanto en el caso de la responsabilidad penal, como de la responsabilidad civil, las formas de imputación son correspondientes a las formas de responsabilidad aplicadas a los particulares, con variantes solo en lo que toca a la específica forma de acción de Estado y las posibles consecuencias dañosas en el campo patrimonial (responsabilidad civil), o, en el campo del derecho penal, en la redacción de tipos penales propios, aplicados a la acción de los agentes públicos (MIRANDA, 2002; LOMBA, 2008).

Es en el campo de la responsabilidad administrativa, funcional y política que el Estado de Derecho presenta regímenes o sistemas normativos diferenciados en relación a los campos originales de la responsabilidad civil y penal. El Estado de Derecho presenta sistemas de normas que procuran sancionar acciones políticas o administrativas de los agentes estatales, con la previsión de tipos o de hipótesis normativas que toman las acciones administrativas o políticas como presupuesto de incidencia de normas.

Como existe la diversidad de funciones estatales, desde funciones administrativas a funciones de gobierno, desde funciones políticas a funciones judiciales, existe una pluralidad de subsistemas normativos de responsabilidad de agentes públicos en el Estado de Derecho. Hay como ejemplos subsistemas normativos para la sanción a los agentes administrativos, en lo que toca a la violación de deberes funcionales como asiduidad, eficiencia, buen trato a la cosa pública, respeto al patrimonio, entre otros. Otra forma de descripción de esos subsistemas son las normas específicas de reglamento de la acción de los magistrados y agentes de las funciones ju-

\footnotetext{
${ }^{5}$ Hoy en día, con la emergencia de la orden jurídica internacional hay una diferenciación del que tenga la responsabilidad del ente público y de sus titulares, en tanto, el inicio génesis de la responsabilidad se mantiene, al paso que esa responsabilidad cuando aplicada al individuo, no lo alcanza, en general, en sus dimensiones privadas, mas si públicas.
} 
risdiccionales. Finalmente, para ilustrar esos ejemplos, las formas de responsabilidad típicas de los agentes políticos, como las desconfianzas y censuras en los sistemas parlamentarios de gobierno, a los crímenes de responsabilidad en los sistemas presidencialistas.

El objeto de investigación de este artículo es la descripción de los sistemas normativos de responsabilidad funcional, administrativa y política de los agentes públicos, en el primer régimen constitucional brasilero, el imperio iniciado en 1822-1824. La opción del artículo por considerar el sistema constitucional de 1824 como sistema de un Estado de Derecho lleva en consideración el estrato temporal de este sistema.

Así, algunas características y concepciones de aquel sistema son distintas a las características y concepciones del Estado de derecho de los siglos XX e XXI. Tomándose las dos dimensiones materiales de las constituciones, las normas de derechos fundamentales y las normas de organización del Estado, el sistema de 1824 era: restricto en los contenidos de derechos fundamentales, limitados a los derechos individuales y de nacionalidad; restricto a la inclusión de personas en el universo de sujetos de los derechos individuales, con la persistencia de confiscación de los esclavos y subalternad de las mujeres; restricto a los derechos políticos con la adopción de formas de aferencia patrimonial para la participación como elector o como ocupante de cargos públicos; 'principesco' en la forma de organización de los ingresos y finanzas públicas y, por consecuencia, 'principesco' en la gestión y ejecución de las funciones estatales, retroalimentando a la pequeña élite gobernante; monárquico con 'sombra' de irresponsabilidad del Emperador; constreñido y evidenciado en la amplitud y acciones de los órganos del Estado.

Las diferencias del Estado del régimen constitucional de 1824 al actual no pueden dispensar la consideración de que el actual Estado de derecho también no logra atender algunas características: de igual forma no universaliza los derechos fundamentales (como los derechos sociales); hay zonas de relatividad en la igualdad del actual Estado; también hay apropiaciones 'principescas o burocráticas' de los órganos de recaudación y del ejercicio funcional de los órganos del Estado. Por tanto, el abordaje de las características del Estado de derecho - sumisión a las normas, existencia de constitución, división de órganos, derechos fundamentales - y entendida aquí en sentido evaluativo, descriptivo y no valorativo. Cuando se usa la expresión evaluativo se quiere decir que son analizadas en el artículo si son detectadas la presencia de las estructuras del Estado de derecho, y no la 
realización de una valoración si son, o no estas estructuras, material e cualitativamente determinantes del Estado de derecho.

La dimensión evaluativa es la descripción con preocupación formal do Estado de derecho, de las estructuras que caracterizan y que el específico objeto de este artículo son las formas de responsabilidad de los agentes públicos en el Estado de 1824. Así que, no abordamos la exploración de elementos substanciales del Estado de Derecho para distinguir, por ejemplo, el Estado liberal del siglo XIX del Estado Democrático de Derecho del siglo XX. El artículo describe como la estructura de responsabilidad adoptada en 1824 - y años siguientes - sirvió de modelo a la tradición constitucional brasilera, en los diversos textos posteriores.

\section{3 \\ CONSIDERACIONES GENERALES SOBRE LA RESPONSABILIDAD POLÍTICA Y FUNCIONAL DE AGENTES PÚBLICOS.}

La responsabilidad política y forma de vinculación gobernante en las reglas de Estado de Derecho, por tanto, con manifestación a partir de la afirmación de los Estados con constituciones, después del siglo XVII y con proliferación en el siglo XIX (LOCKE, 1998; CONSTANT, 1815). La responsabilidad política y la responsabilidad entre gobernantes y gobernados, derivada del vínculo político entre esos actores (CHEIBUBI e PRZEWORSKI, 1997), con repercusiones sancionatorias o consecuencias jurídicas en el cargo o función de agente, en función de la violación de ciertas atribuciones del cargo, o por realizar conductas típicas ofensivas a la sinecura del cargo, o conductas ofensivas a la existencia o de las estructuras del Estado. Las formas y los sistemas de gobierno imprimen modelos propios a la responsabilidad, variando entre la república y la monarquía, y también entre el sistema unipersonal y el sistema bipartito de gobierno (LOMBA, 2008).

En algunas formas de responsabilidad política, además de las consecuencias jurídicas sobre el cargo existe la imposición de sanciones pecuniarias, restrictivas de derechos, restrictivas de la libertad, o incluso la pena capital. La responsabilidad política es una forma de límite constitucional del ejercicio funcional del agente político. La responsabilidad política tiene procesalista propia y normalizada, variable entre las formas o 
sistemas de gobiernos adoptados por cada Estado (difiriendo en el presidencialismo y el parlamentarismo). La responsabilidad ocurre en el ambiente propio del Estado de Derecho (LOMBA, 2008).

El sistema de responsabilidad política es destinado a los agentes que por la naturaleza del cargo ejercen funciones típicas de gobierno, o de dirección política del Estado. Lo que se nota es que las formas de responsabilidad política dirigidas a los agentes del Ejecutivo no incluían los agentes del Legislativo, o incluso a los agentes del judiciario. Las formas aplicadas a los agentes del judiciario y del legislativo son procesal e substancialmente distintas a aquellas del ejecutivo.

Tal perspectiva es explicada por el hecho de que el presidencialismo siempre se presentó como una forma concentrada de poder unipersonal, el trauma del despotismo siempre marcó ese sistema. En cuanto a eso, el legislativo, por su naturaleza colectiva ya contaría con dimensiones internas de actuación para vedar la centralización y, por último, el judiciario solo pasa a adquirir mayor relevancia el escenario político en el inicio del siglo XX. Hoy en día, en tanto, se percibe que en un escenario de corrupción sistemática ${ }^{6}$, igualitaria entre los poderes, las formas blandas de responsabilidad política del legislativo y del judiciario son perjudiciales para el desempeño político institucional, mientras que las formas de responsabilidad del ejecutivo pueden, frente a un parlamento corrupto, inaugurar fenómenos de control político extraños al presidencialismo.

Al lado de las formas de responsabilidad política existen formas de responsabilidad propias de otras funciones o de otros agentes públicos. Los ejemplos de estas otras formas son las normas propias de los agentes del judiciario que potencialmente están introducidos a los dictámenes de responsabilidad relacionados a la prestación jurisdiccional. Aunque en muchos casos el tratamiento de los posibles delitos funcionales de los magistrados puedan estar redactados en el mismo texto legal de los delitos de los agentes políticos, los tipos y las hipótesis de estos delitos son distintas a aquellas de los agentes políticos. Uno de los elementos que destaca la diferencia entre los agentes del judiciario y los agentes políticos es el distanciamiento de la responsabilidad de los magistrados de vínculos representativos con los electores. Como los magistrados no se someten a la rutina de elecciones y sufragio, los delitos que están potencialmente incluidos son mucho más descriptivos de violaciones de las funciones en la prestación

\footnotetext{
${ }^{6}$ Expresión utilizada en el sentido conferido por John Wallis (2004). http://www.nber.org/papers/w10952.pdf
} 
jurisdiccional que las posibles frustraciones a los compromisos políticos, o incluso de posibles actos atentatorios a la soberanía o la administración pública.

Por otro lado, la responsabilidad política de los parlamentarios se orienta por razones de censura y eliminación del cargo primeramente ligadas al juicio criminal quizá existente contra ellos. El juicio criminal aquí mencionado no tienen nada de original a los delitos comunes, previstos en la legislación penal ordinaria. Lo que el sistema de los parlamentarios hace es determinar reglas procesales específicas de procesamiento penal - foro privilegiado, el vedado de las prisiones procesales de que la existencia de un sistema de previsión de normas con conductas típicas de violación de deberes funcionales, o de forma específica de responsabilidad política.

Las normas de responsabilidad de los parlamentarios se fueron formando en la historia brasilera por normativas por disposiciones reglamentarias con previsiones normativas que tenían por contenido normativo disposiciones de buenas conductas y padrones éticos (CÁMARA DE LOS DIPUTADOS BRASIL, 1881), o como consecuencia de violaciones de impedimentos de ocupaciones de cargos, de patrocinio de intereses conflictantes con el cargo de parlamentario. Para ejemplificar, las disposiciones sobre decoro parlamentario solo ganarán previsión constitucional y ordenamiento de 1946 (CHERCHI, 2009). La constitución imperial no traía cualquier previsión especifica de responsabilidad de los parlamentarios. No había previsión en la constitución de 1824 de que el popular representase o peticionase imputando ilícitos a los parlamentares.

\section{EL SISTEMA DE RESPONSABILIDAD POLÍTICA $Y$ FUNCIONAL DEL IMPERIO BRASILERO.}

El modelo de responsabilidad política y funcional nacional se inicio $^{7}$ con las normas de Imperio, en la constitución de 1824. El sistema

\footnotetext{
${ }^{7}$ Interesante notar que el camino constitucional de 1824 se asemeja un poco con la Constitución de Reino Unido de Portugal de 1822, en este texto estaban garantizada una semi-autonomia institucional de territorio brasilero, con la existencia de tribunales proprios. De esa forma, en lo que se refiere a la responsabilidad política en los primordios del Imperio Brasilero no existe gran innovación con la Constitución de 1824, existe, en verdad, fuertes inspiraciones de la Constitución del Reino Unido. Para mas detalles sobre el texto de 1822 vide BONAVIDES (2000) http://www.scielo.br/pdf/ea/v14n40/v14n40a16.pdf e http://www.viriatosoromenho-marques.com/Imagens/PDFs/Constituicao\%201822-1998.pdf
} 
cuadripartido de órganos estatales, dividido entre el moderador, el ejecutivo, el legislativo y el judiciario, sobre decoro parlamentario solo ganarán previsión constitucional en el ordenamiento y para otros agentes públicos específicas modalidades de responsabilidad funcional.

Una posible primera clasificación del sistema constitucional de 1824 divide la responsabilidad política en dos modalidades de responsabilidad. Una de las formas de responsabilidad, fue consecuencia de la adopción del sistema parlamentario del gobierno en 1847 y que importó en la atribución de responsabilidad al jefe del Consejo de Ministros, y al Consejo:

\begin{abstract}
Crea un Presidente del Consejo de los Ministros.
Tomando en consideración la conveniencia de dar al Ministerio una organización más adaptada a las condiciones del Sistema Representativo: He aquí por bien crear un Presidente de Consejo de los Ministros; cumpliendo al dicho Consejo organizar su Regulación, que será sometida a la Mi Imperial Ovacionar. Francisco de Paula Sousa y Mello, Mi Consejo d'Estado, Ministro y Secretario de Estado de los Negocios del Imperio, el que tenga así entendido, y haga ejecutar. Palacio de Rio de Janeiro en viente de Julio de mil ochocientos cuarenta y siete, vigésimo sexto de la Independencia y del Imperio.

Con la Rubrica de Su Majestad el Emperador. (IMPERIO DE BRASIL DECRETO $\mathrm{N}^{\circ} 523,1847$ )
\end{abstract}

La primera forma de responsabilidad descrita en el párrafo anterior, la del parlamentarismo de 1847-1889, era construida con el sistema de responsabilidad política del cual la sanción de pérdida del cargo no era consecuencia de la imputación de delito. Era juicio político realizado de la lógica de confianza-desconfianza, conveniencia y oportunidad.

De manera diferente a aquella típica de los sistemas parlamentarios, el sistema imperial brasilero en el repaso del juicio político de confianza-desconfianza, censura del Jefe de los Ministros, en el Parlamento. Quien hacía el juicio político era el Emperador (HORBACH, 2007). Por esto, se prodigó la expresión de que el sistema parlamentario imperial brasilero era un 'parlamentarismo a las aversiones'.

En la otra forma de responsabilidad política importaba la imputación de conductas ilícitas a los ocupantes de cargos públicos. Ya con relación a esta segunda forma de responsabilidad, con la imputación de delito y las consecuencias, de ahí, la Constitución Imperial hizo previsión de conductas tenidas como ilícitos político-constitucionales para algunos agentes 
públicos. El sistema de normas con previsión de ilícitos era dirigido a los agentes del Ejecutivo y del judiciario.

La segunda clasificado posible es la de que el texto de 1824 imputa la responsabilidad política de los agentes públicos del Ejecutivo que eran los Consejeros de Estado e los Ministros del Gabinete, y de manera diversa la responsabilidad funcional de los miembros del judiciario.

\section{EL SISTEMA DE RESPONSABILIZACIÓN FUNCIONAL DE LOS AGENTES DEL JUDICIARIO EN EL IMPERIO.}

Los agentes del judiciario en el Imperio se sujetaban al sistema de responsabilidad proprio de la magistratura, sin el contenido de responsabilidad política idéntico al de los agentes políticos:

Art. 156. Todos los Jueces de Derecho, y los Oficiales de Justicia son responsables por los abusos de poder, y prevaricaciones, que cometieren en el ejercicio de sus Empleos; esta responsabilidad si será efectiva por Ley a reglamentar.

Art. 157. Por soborno, dádivas, malversación, y solicitud de ventaja indebida habrá contra ellos acción popular, que podrá ser intentada dentro del ano, y día por el propio querellante, o por cualquier del Pueblo, guardada la orden del Proceso establecida en la Ley (BRASIL CONSTITUCIÓN DE 1824, 1824).

La Ley de 14 de junio de 1831 definía que competía al/os Regente/s y a los Presidentes provinciales 'suspender a los Magistrados [...] , en Consejos, escuchando al Magistrado, y procediendo en la forma do art. 154 da Constitución'. El artículo 154 de la Constitución imperial mencionado en el texto de la ley determinaba que el Emperador podía suspender a los magistrados acusados de ilícitos funcionales. El que la ley hizo fue extender a los presidentes provinciales la competencia antes atribuida a la Regencia y al Monarca.

En consecuencia, el artículo 11 da Ley $n^{\circ} 16$, de 1834 - Hecho adicional -, trató de definir el foro para el juzgamiento de los delitos de responsabilidad de los magistrados:

Art. 11. También compete a las Asambleas Legislativas Provinciales:

$\S 7^{\circ}$ Decretar la suspensión, y aun así la dimisión de Magistrado, contra quien hubiera queja de responsabilidad, siendo el escuchado, y otorgándose lugar a la defensa. (IMPERIO DE BRASIL LEY $\mathrm{N}^{\circ}$ $16,1834)$ 
En 1840, la Ley de la interpretación otorga una nueva redacción al dispositivo constitucional de la responsabilidad de los magistrados:

\begin{abstract}
Art. $4^{\circ}$ En la palabra - Magistrado - que usa el art. $11 \S 7^{\circ}$ del Acto Adicional, no se comprenden a los Miembros de las Relaciones, y Tribunales Superiores.

Art. $5^{\circ}$ En la decretación de suspensión, o dimisión de los Magistrados, proceden a las Asambleas Provinciales como Tribunal de Justicia. Solamente pueden, por tanto, imponer tales penas en virtud de queja, por crimen de responsabilidad a la que ellas están impuestas por Leyes criminales anteriores, observando la forma de proceso para tales casos anteriormente establecida.

Art. $6^{\circ} \mathrm{El}$ Decreto de suspensión, o dimisión, deberá contener: $1^{\circ}$, el relatorio del hecho; $2^{\circ}$, la citación de la Ley, en que el Magistrado está inmerso; $3^{\circ}$, una suscita exposición de los fundamentos capitales de la decisión tomada. (IMPERIO DE BRASIL LEY N ${ }^{\circ} 105$, 1840)
\end{abstract}

\title{
6 LA IRRESPONSABILIDAD DEL EMPERADOR, LA RESPONSABILIDAD DE LOS CONSEJEROS $Y$ MINISTROS.
}

El modelo de responsabilidad política del Imperio de Brasil, el Emperador era irresponsable políticamente: 'Art. 99. La persona del Emperador es inviolable, y Sagrada: Ella no está sujeta a responsabilidad alguna'. (BRASIL CONSTITUCIÓN DE 1824, 1824)

En la Constitución imperial, el Ejecutivo se divide entre la figura irresponsable del Emperador, de acuerdo con el art. 99, y el Ministerio, y era este último sujeto de responsabilidad. El Ministerio debería prestar la guarda de los altos bienes del Estado y no deberían adoptar conductas consideradas reprobables a esos agentes del Estado, determinados por la Constitución Imperial.:

Art. 133. Los Ministros de Estado serán responsables

I. Por traición.

II. Por dádivas, malversación, y solicitud de ventaja indebida.

III. Por abuso de Poder.

IV. Por la falta de observancia de la ley.

V. Por los que obraren contra la Libertad, seguridad,o propriedad de los ciudadanos.

VI. Por cualquier disipación de los bienes públicos.

$[\ldots]$ 
Art. 135. No salva a los Ministros de la responsabilidad la orden del Emperador vocal, o por escrito. (BRASIL CONSTITUCIÓN DEL IMPERIO DE BRASIL, 1824)

Además del Ministerio, existía el órgano de consejo del Emperador que era el Consejo de Estado. El Consejo de Estado tuvo varias composiciones en la Constitución con alteraciones e, inclusive, la supresión en determinado período (IMPERIO DE BRASIL LEY DE 12 DE OCTUBRE DE 1832, 1832; IMPERIO DE BRASIL LEY N ${ }^{\circ} 16,1834$; IMPERIO DE BRASIL LEY N 105 , 1840; IMPERIO DE BRASIL LEY Nº 234 , 1841).

De la misma forma que el Ministerio, la Constitución prescribía en el art. 143 que 'Son responsables los Consejeros de Estado por los consejos, que dieren, opuestos a las Leyes, y al interés del Estado, manifiestamente dolosos' (BRASIL CONSTITUCIÓN DEL IMPERIO DE BRASIL, 1824).

\section{LA LEY IMPERIAL DE 15 DE OCTUBRE DE 1827.}

Los delitos de responsabilidad del Ministerio estaban disciplinados en reglas específicas por exigencia del artículo 134 de la Constitución Imperial que determinaba que 'Una Ley particular especificará la naturaleza de estos delitos, y la manera de proceder contra ellos' (BRASIL CONSTITUCIÓN DEL IMPERIO DO BRASIL, 1824).

La Ley de 15 de octubre de 1827 definió los delitos de responsabilidad de los Ministros de Estado (IMPERIO DE BRASIL LEY DE 15 OCTUBRE DE 1827, 1827). En la misma ley fueron disciplinadas las reglas de responsabilidad de los Consejeros de Estado. En el caso de los Consejeros de Estado, consideradas las modificaciones (1832), y hasta incluso la extinción en 1834, la última ley sobre el asunto fue la de 1841 (que recreó el Consejo) y traía la siguiente redacción:

Art. $4^{\circ}$ Los Consejeros de Estado serán responsables por los Consejos, que dieren al Emperador, opuestos a la Constitución, y a los intereses del Estado, en los asuntos relativos al ejercicio del Poder Moderador; debiendo ser juzgados, en tales casos, por el Senado, en la forma de la Ley de la responsabilidad de los Ministros de Estado. (IMPERIO DE BRASIL LEY N 234,1841 ) 


\section{LA ESTRUCTURA Y EL PROCESO EN LA LEY IMPERIAL N 15 DE 1827.}

La estructura da ley de responsabilidad de los Ministros y de los Consejeros es la siguiente:

a) Del art. $1^{\circ}$ al art. $6^{\circ}$ define los tipos de responsabilidad de los Ministros previstos en la Constitucional: la traición - art. $1^{\circ}$-; la dadiva, el soborno, la solicitud de ventaja indebida - art. $2^{\circ}$-; el abuso de poder art. $3^{\circ}$-; falta de observancia de la ley - art. $4^{\circ}$-; obrar contra la seguridad, la libertad o la propiedad de los ciudadanos - art. $5^{\circ}$-; disipación de bienes públicos - art. $6^{\circ}$-.

Como se puede ver, la estructura de las conductas consideradas reprobables, y de los bienes del Estado que merecían especial protección fueron definidas en la Ley de 1827 y se acabaron tornando en modelo general seguido por las normas sobre el asunto en la República.

b) Las sanciones envolvían desde la pena capital, pasando por deshonras públicas, inhabilitación al empleo, prohibición de ocupación de cargos públicos, prisión, suspensión por tiempos variados del ejercicio de cualquier empleo, y la reparación del daño provocado, en los casos en los cuales había daño material.

En estos aspectos la Ley imperial se diferenciaba de las normas adoptadas por las leyes y constituciones republicanas que fueron editadas posteriormente. En la normatividad imperial había la incorporación al sistema punitivo de penas típicas del derecho penal. La responsabilidad ministerial era por tanto penal, administrativa y política, simultáneamente. Así que, el sistema imperial brasilero adoptaba una fórmula que había sido superada en la Inglaterra, ejemplo de sistema monárquico parlamentario.

En la Inglaterra, aunque el 'impeachment' ha surgido como forma de punición criminal de nobles, desde el siglo XVII había migrado para formas de exclusiva responsabilidad política, sin consecuencias punitivas de sanciones físicas o privativas de libertad (UK PARLIAMENT, 2016). El sistema imperial nacional discrepó de la Monarquía británica por adoptar la forma punitiva combinada, penal, política y administrativa.

c) El art. $7^{\circ}$ de la Ley trataba específicamente de los dos delitos tipificados a los Consejeros de Estado: 'Los Consejeros de Estado son responsables por los consejos que dieren: $1^{\circ}$ Siendo opuesto a las leyes. $2^{\circ}$ Siendo contra los intereses del Estado, si fueren manifiestamente dolosos'. 
En complemento, decía que 'incurren en las mismas penas, en que los Ministros y Secretarios de Estado incurren por hechos análogos a este' (IMPERIO DE BRASIL LEY DE 15 OCTUBRE DE 1827, 1827).

d) La denuncia podía ser presentada por cualquier ciudadano. En la propia ley se menciona que tal prerrogativa era resultado del derecho de petición insertado en la constitución imperial, en el art. 179, XXX. Además de los ciudadanos, los miembros de cualquier cámara también podían patrocinar la petición de denuncia de delito de responsabilidad por Ministros.

Por cierto el universo de ciudadanos debía ser entendido dentro de las limitaciones del régimen de 1824. No había universo igualitario, pero sí limitaciones por sexo e ingresos que discriminaban aquellos que podían ser comprendidos por ciudadanos.

e) La legislación presentaba plazos preceptivo para el ejercicio del derecho de petición. Para los miembros de las cámaras, el plazo de dos legislaturas, a partir de la fecha de comisión del ilícito. Al ciudadano, el plazo de 3 años a partir de la práctica del delito.

f) El procesamiento inicial de la denuncia era hecha en la Cámara. El proceso tenia, como hoy, naturaleza bifásica, dividiéndose las responsabilidades entre Cámara e Senado.

g) La denuncia era recibida y encaminada a la comisión especial. La comisión podría solicitar las pruebas que considerase necesarias para el encaminamiento y escrutinio de la denuncia. Después de las averiguaciones realizadas, la comisión podía entender haber indicios de la práctica de ilícito. Después de la apreciación preliminar, nuevas reuniones de la comisión (o de otra nombrada para este fin) se producía un dictamen sobre la denuncia. El parecer era sometido a la cámara. Siguiendo la regla del art. 25 de la Constitución, la aprobación de la denuncia era por mayoría absoluta.

h) Aceptada la denuncia del denunciado ya sufría restricciones de naturaleza preventivas:

$1^{\circ}$ Permanecer el acusado suspenso del ejercicio de todas las funciones públicas, hasta final sentencia, e inhabilitado en este tiempo para ser propuesto la otra empleo, o en el provisto.

$2^{\circ}$ Permanecer sujeto a la acusación criminal.

$3^{\circ}$ Ser preso en los casos, en que por la Ley tiene lugar la prisión. $4^{\circ}$ Suspenderle la mitad del ordenado, el sueldo, que tenga; o perderlo efectivamente, si no fuera finalmente absuelto. (IMPERIO DE BRASIL LEY DE 15 OCTUBRE DE 1827, 1827) 
La Cámara constituía comisión para presentar la denuncia al Senado. Esta comisión presentaba el parecer de la acusación a la casa del Senado.

i) De acuerdo con la redacción de la ley, el Senado se convertía en Tribunal de Justicia y ' Todo senador son Jueces competentes para que conocieren de los crímenes de responsabilidad' (IMPERIO DE BRASIL LE Y DE 15 OCTUBRE DE 1827, 1827).

j) La lista de impedimentos o suspensiones era la siguiente:

\footnotetext{
$1^{\circ}$ Los que tuvieran parentesco en línea reta de ascendentes, o descendentes, suegro, y yerno; en línea colateral hermano, cuñados, en cuanto dure es relación de cuñado, y los primos co-hermanos.

$2^{\circ}$ Los que tuvieron depuestos como testigo en la formación de la culpa, o del proceso.

$3^{\circ}$ Los que tuvieron demanda por si o sus mujeres sobre mayor parte de sus bienes, y el litigio ha sido propuesto antes de la acusación. $4^{\text {o }}$ Los que tuvieron herederos presuntivos. (IMPERIO DE BRASIL LEY DE 15 OCTUBRE DE 1827, 1827)
}

Además de los casos de impedimento o suspensión, podía ocurrir la recusación no fundamentada de 6 Senadores.

k) Después la comunicación del recibimiento de la difamación, se determinaba el plazo para la sesión de juzgamiento. Pero la ley, el juzgamiento era pautado por la contradicción entre la comisión de acusación y la defensa del acusado. Senadores pudieran encaminar preguntas durante la sesión de juzgamiento.

1) La ley preveia la realización de sesión secreta para la verificación de la suficiencia de todo lo que fue producido en el juzgamiento. Solamente con la confirmación de la suficiencia se podía encaminar la materia al juzgamiento por el Tribunal del Senado.

m) La sesión definía la procedencia o la improcedencia de la acusación. Después de esto, el Presidente encaminaba los requisitos de aplicación de la pena: al grado máximo, medio o mínimo de penalidad.

n) De la decisión cabía como único recurso, los embargos. El plazo máximo para la presentación era de diez días después de la sesión de juzgamiento.

El sistema de responsabilidad ministerial y consejería perduró durante todo el Imperio. Con la proclamación republicana se tornó sistema 
de normas con cesación de existencia, por las mudanzas de forma de gobierno y sistema de gobierno, con el advenimiento de la orden constitucional de 1889.

\section{CONCLUSIÓN: LA PERMANENCIA DE LAS ESTRUCTURAS DE LA RESPONSABILIDAD DEL RÉGIMEN DE 1824 EN LAS CONSTITUCIONES POSTERIORES.}

Las estructuras de la responsabilidad del régimen de 1824 servirán a los modelos constitucionales posteriores. La diferencia destacada del régimen imperial en relación a los posteriores regímenes republicanos está en la inclusión del jefe del ejecutivo, o Presidente de la República, en el rol de los sujetos pasibles de responsabilidad.

La responsabilidad de Ministros de Estado, y del jefe del Ejecutivo del período imperial, el Jefe del Gabinete, y de los Consejeros de Estado, muestra que la responsabilidad de la dirección del ejecutivo está presente desde el régimen de 1824. El régimen republicano alteró las disposiciones sobre responsabilidades de los miembros del ejecutivo determinando el juzgamiento por el STF, y no más por las casas legislativas.

La forma básica de procesamiento y juzgamiento de los crímenes envolviendo al Presidente de la República, blasfemia bifásico, con la admisibilidad en la Cámara y el juzgamiento en el Senado, es tradición iniciada en el juzgamiento del período imperial, de Ministros y Consejeros. Tal como hoy, y en el comienzo del régimen republicano, la acusación era analizada por la Cámara y, admitida, juzgada por el Senado.

Las autoridades atípicas incluidas en el rol de sujetos pasibles de imputación de crimen de responsabilidad, en el período republicano, como los miembros del Judiciario - Ministros del STF -, ya eran pasibles de punición por responsabilidad en el sistema de 1824. El sistema de responsabilidad de 1824 ya preveía que magistrados respondiesen por delitos funcionales. En la verdad, el sistema de 1824 era tan amplios cuando el de 1991, ya que incluía todos los jueces, al contrario de que prevaleció en el 


\section{sistema republicano, de inclusión solamente de los Ministros do STF y jui- cios federales ${ }^{8}$.}

\section{OBRAS CITADAS}

BRASIL CONSTITUCIÓN DE 1824. Constitución del Imperio de Brasil de 25 de marzo de 1824. Planalto legislación, Brasília, 1824. Disponible en: <http://www.planalto.gov.br/ccivil_03/Constituicao/Constituicao24.htm>. Acesso em: 02 abr. 2016.

BRASIL CONSTITUCIÓN DEL IMPERIO DE BRASIL. Constitución del Imperio de Brasil de 25 de marzo de 1824. Planalto legislación, Brasília, 1824. Disponible en: <http://www.planalto.gov.br/ccivil_03/Constituicao/Constituicao24.htm>. Acceso em: 02 abr. 2016.

CÁMARA DE LOS DIPUTADOS BRASIL. Regimiento interno de la Cámara de Diputados. Biblioteca digital de la Cámara, 1881. Disponible en: <file: /// C: /Users/walmott/Downloads/regimento_camara_1870_1881.pdf>. Acceso en: 16 de abril. 2009.

CHEIBUBI, J. A .; PRZEWORSKI, A. Democracia, elecciones y responsabilidad política. Revista brasileña de ciencias sociales, São Paulo, fev. 1997.

CHERCHI, G. S. Renuncia del mandato parlamentario en la Cámara de Diputados por falta de ética o quiebra del decoro parlamentario. Biblioteca digital Cámara, 2009. Disponible en: <file: /// C: /Users/walmott/Downloads/renuncia_mandato_cherchi.pdf>. Acceso en: 09 de abril. 2016.

CONSTANT, B. Principios de politique - aplicable a los guevernemens représentatifs. París: Chez Alexy Eymery, 1815.

GAY, O .; DAVIES, N. Impeachment. House of Commons Library. Londres, p. 1-6. 2011.

HORBACH, C. B. El parlamentarismo en el Imperio de Brasil (II). Revista de información legislativa, Brasilia, abr.-jun 2007. 213-231.

De acuerdo con lo establecido en la Ley Orgánica 15/1999, de las Comunidades Europeas, 1899 / decreto 523-20-julio-1847 hasta 560.333-publicacaooriginal-83096-pe.html>. Acceso en: 09 de abril. 2016.

De acuerdo con lo establecido en la Ley Orgánica del Poder Legislativo, en el marco de la Convención de las Naciones Unidas sobre el Cambio Climático. 10-1832.htm>. Acceso en: 03 de abril. 2016.

IMPERIO DEL BRASIL LEY DE 15 OCTUBRE DE 1827. Ley de 15 de octubre de 1827. Cámara de Diputados - legislación informatizada, 1827. Disponible en: 〈http://www2.camara.leg.br/legin/fed/lei_sn/1824-1899/lei-38389-15-outubro-1827-566674-publicacaooriginal-90212-pl.html>. Acceso en: 16 abr. 2016.

\footnotetext{
${ }^{8}$ A partir de 1891 hubo la inclusión de las siguientes autoridades como pasibles de práctica crímenes de responsabilidad: presidente, ministros de Estado e ministros do STF. Presidente y Ministros de Estado (estos últimos si cometiesen crímenes conexos a los del presidente), juzgados por el sistema bifásico, Cámara-Senado. Los ministros del STF juzgados por el Senado. Los ministros de Estado, si no hubiese la conexión, del STF. La Constitución republicana prevía que el STF juzgaría los jueces federales por crímenes de responsabilidad. La posible responsalidad de los juícios estaduales permanencia a la competencia de cada Estado da federación.
} 
IMPERIO DEL BRASIL LEY No 105. Ley n ${ }^{\circ} 105$ de 12 de mayo de 1840. Planalto legislação, 1840. Disponible en: <http://www.planalto.gov.br/ccivil_03/LEIS/LIM/LIM105.htm>. Acceso en: 03 abr. 2016.

IMPERIO DEL BRASIL LEY N 16 . Ley n ${ }^{\circ} 16$ de 12 de agosto de 1834 . Planalto legislação, 1834. Disponible en: <http://www.planalto.gov.br/ccivil_03/LEIS/LIM/LIM16.htm>. Acceso en: 03 abr. 2016.

IMPERIO DEL BRASIL LEY N 234. Ley n ${ }^{\circ} 234$ de 23 de noviembre de 1841. Planalto legislação, 1841. Disponivel em: <http://www.planalto.gov.br/ccivil_03/leis/LIM/LIM234.htm>. Acceso en: 03 abr. 2016.

LOCKE, J. Dos tratados sobre el gobierno. En el caso de las mujeres.

LOMBA, P. Teoría de la responsabilidad política. En el caso de las mujeres.

MIRANDA, J. Teoría del Estado y de la Constitución. En el caso de las mujeres.

UK PARLIAMENT. Juicio político. UK Parliament Glossary, 2016. Disponible en: <http://researchbriefings.parliament.uk/ResearchBriefing/Summary/SN02666>. Acceso en: 03 de abril. 2016. 